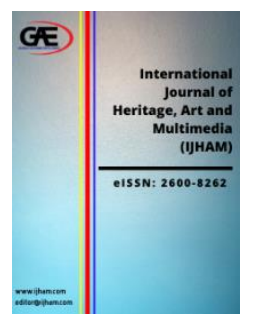

\author{
International Journal of Heritage, Art and \\ Multimedia (IJHAM) \\ Journal Website: http://ijham.com/ \\ eISSN: $2600-8262$
}

\title{
"SAFE!": YOUTH PERCEPTION OF TAMAN PERBANDARAN TENGKU ANIS, KOTA BHARU
}

\author{
Mohd Hilmi Harun $^{1 *}$, Siti Aisyah Muhammad ${ }^{2}$, Nik Ashri Nik Harun ${ }^{3 *}$, Nooraziah Ahmad \\ 1 Department of Creative Technology Design, Universiti Malaysia Kelantan, Malaysia. \\ Email: hilmiharun@umk.edu.my \\ 2 Department of Science in Architecture, Universiti Malaysia Kelantan, Malaysia. \\ Email: aisyah@umk.edu.my \\ 3 Department of Creative Technology Design, Universiti Malaysia Kelantan, Malaysia. \\ Email: nikashri@umk.edu.my \\ 4 Department of Creative Technology Design, Universiti Malaysia Kelantan, Malaysia. \\ Email: nooraziah@umk.edu.my \\ * Corresponding Author
}

\section{Article Info:}

\section{Article history:}

Received date: 26.02 .2020

Revised date: 27.02 .2020

Accepted date: 04.03.2020

Published date: 10.03 .2020

\section{To cite this document:}

Harun, M. H., Muhammad, S. A., Harun, N. A. N., \& Ahmad, N. (2020). "Safe!": Youth Perception of Taman Perbandaran Tengku Anis, Kota Bharu. International Journal of Heritage, Art and Multimedia, 3 (8), 20-27.

DOI: $10.35631 /$ IJHAM.38003.

\begin{abstract}
:
Social and cultural influences the community in many ways either directly or indirectly. Thus, this paper argues about the community perception focusing on the age of youth towards the Public Park in Kota Bharu regarding their expectation and their emotions upon this public park. Questionnaire regarding the youth's perception about the relationship between the feelings and the Public Park utilization has been done as well as using observation and Semantic Differential Method. The result shows by the exploratory factor analysis based on eigenvalue cut off resulting four components regard to the facilities provided in Taman Perbandaran Tengku Anis with a total cumulative $72.324 \%$ while there are three components explained their feelings with total cumulative $72.923 \%$. Consequently, the expectations and feelings of the youth as the users or visitors at this park is related to the component attractions of this park. Although this park can be considered as a successful urban public open space in terms of the physical environment designation that offered plenty of human activities onto it, the youth have their own on this public space.
\end{abstract}

\section{Keywords:}

Public Park, Perception, Socio-culture, Place-making, Teenagers 


\section{Introduction}

The socio-cultural expanded from the remote people who live in Kelantan such as the civil servants, students and also perhaps through the social media. In such, the socio-activities that employed the spaces at the public park are no longer limited but parallel to the major cities in Malaysia as well especially by the youth. However, the current trend of the socio-culture is unready to be catered by the facilities provided. Accordingly, there are facilities such as the outdoor fitness equipment that used as parkour plot, badminton court become the roller blade court and aerobic exercise area. As a result, there are some activities that are decreasingly engaged with the facilities provided. As the human activities slightly expanded, the utilization of the facilities provided becomes crowded. Therefore, this paper aims to explain the community perception focusing the age of the youth on the Public Park in Kota Bharu where the cultural influences acted likely time bomb as the youth freely doing the activities where the previous generation are seldom to do due to the limitation of the socio-cultural adaptation and openness. This Public Park is expected as one of the public spaces where the local can-do leisure activities or seeing others doing it.

Literature review have indicated that the built environment incudes the succession of spaces that people have to build to shelter and shape the full range of their activities across the time, place and culture as well as across social, economic and political structure (Dobbins, 2009). It can be pictured as buildings, lots, blocks, streets, parking, utilities, neighbourhood, districts, towns and cities, moreover the regions. According to Mario et al. (2019), Creighton (2005) and Ismail (2015), the idea of public involvement is advocated to reduce citizen scepticism toward government, build stakeholder consensus in government, and enhance administrative decision making. Likely in Malaysia, public participation becomes an important element in governmental decision making and planning processes (Khadzali \& Zan, 2018). According to Mohamed Anuar \& Saruwono (2018), public participation is not only a good possibility for better planning but also a requirement as stated in planning law where the public have the right involve in decision making process. In landscape architecture and urban planning, understandings of the contribution of public spaces to the city have been developed as early $20^{\text {th }}$ century. Broad changes and ultimate effect of mass development in the city centre started in 1960s has extended greater respect into a space is a social space such as a town square that is generally open and accessible. Public space is developed to serve as major activity areas in the city or town. It was designed to attract all races and cultures and to provide places for attention to the integration of uses. The spaces affect many people and their design could be replicated in several other public parks (Jamil, 2002). As highlighted by Isabelle, Heidi \& Gerald (2015), and Lauren et al. (2018), parks are primarily designed for recreation and can give enormous benefits to the neighbourhoods and community by improving health, social well-being and enhancing enjoyment of the local environment. Likewise, benefits of leisure also cover physical health, psychosocial well-being, self-actualization, spirituality and selfidentity, family bonding, child development, environmental education and social skills development (Veal \& Lynch, 2001). The important role of urban public spaces is recognized both in the character and the life they bring to towns and cities around the world as portray the place making which is the process of making good place by reviewing substantive dimension in public spaces design such as social, visual and functional.

Therefore, which regards to the understanding the youth perception of the public park, this research aims to identify the main attraction of this park and the youth feelings while utilizing this public park, there are two main significant factors need to be reconnoitred. This research aims to identify the main attraction and of this park and the youth feelings while utilizing this public park. 


\section{Methodology}

In order to achieve the objectives of this research, a case study has been done in a public park in Kota Bharu, named as Taman Perbandaran Tengku Anis (TPTA). Figure 1 shows the map of TPTA itself. This Public Park was built in 2004 within 7.422 hectares $^{2}$ space. 50 questionnaires had been conducted to the visitors focusing the age of youth; (see Figure 2) 15 years old to 40 years old according to the Ministry of Youth and Sports Malaysia. There was 48 questionnaires were accepted to analyse (34 male and 14 female). The result from the survey was analysed using SPSS 21 in reaching the reliability and factor analysis. The results from the Semantic Differential Methodology will show the clustered feelings of the youth towards the utilization this public park. The relationship between the physical environment and their feelings is discussed further.

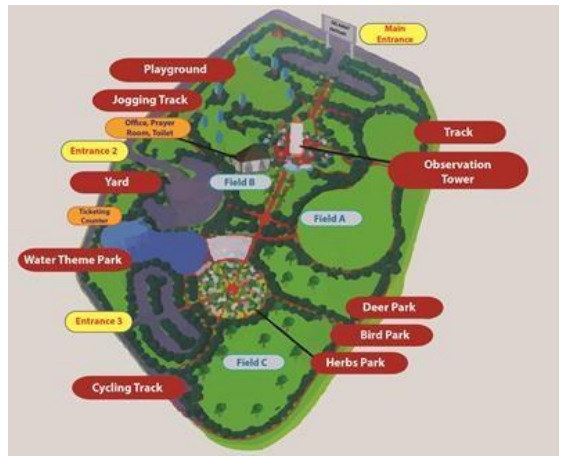

Figure 1: Map of Taman Perbandaran Tengku Anis

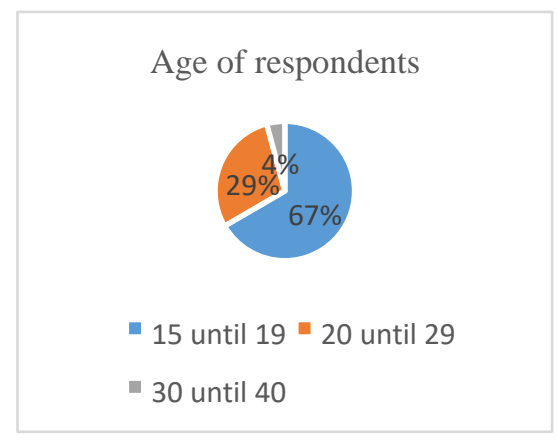

Figure 2: Age of The Sample

\section{Findings and Analysis}

According to Muhammad (2019), the broadest sense the elements of urban design may be organized in three spheres, each of which is interactive with each other's; the physical environment, human activity and it shows at Figure 3, and the connections between them. These three spheres have been created as the main core of the questionnaire for this research. Factor analysis investigates the correlations among the subsets of the responses to the bipolar pairs and the groups that have correlated variables, and such that, each group is largely independent of the others. Exploratory factor analysis was employed to identify the groups, which might explain most of the variance in the data. 


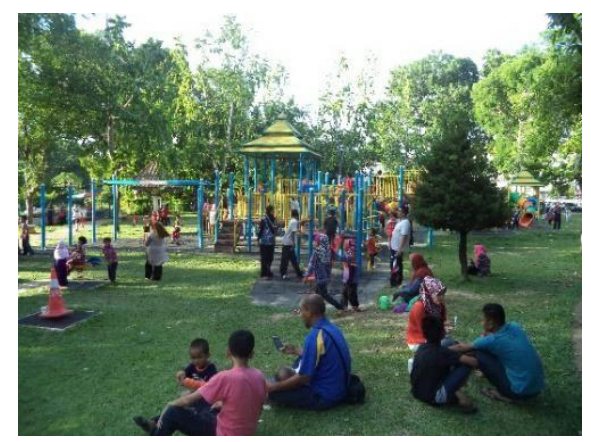

\section{Figure 3: Visitors Activities at The Playground}

The first significant finding about this paper is elaborated by the exploratory factor analysis based on eigenvalue cut off resulting four factors explained attraction in Taman Perbandaran Tengku Anis one of them is show on Figure 4, Aerobic exercise at the court with a total cumulative $72.324 \%$. The results of the principal components analysis are presented by the physical environment, human activity and also the connection between them. The interpretation of these factors resulted as such dimension; Component 1 (29.801\%), Component 2 (20.985\%), Component 3 (13.505\%) and Component 4 (8.032\%). There is huge engagement of the third sphere (the connection between them) in this Public Park as the visitors offered plenty of activities within this Public Park.

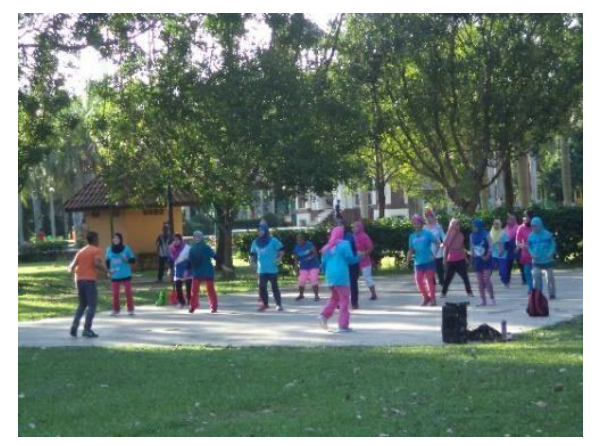

Figure 4: Aerobic Exercise at The Court

According to the result above, there are four factors that engage people to come to this park. The factors are merely having been clustered based on the human activities that connected to the facilities provided. This shows that there is connection between the physical environment and the human behaviour but the essence of the functions of the facilities has been expanded. For instance, the first factor clustered four components (Table 1) which basically address the general view of a park features. The second factor consist of five components that highlighted facilities provided in this park that may become the major activities utilized to it. Furthermore, the third factor is clustered as sight-seeing and animal petting where both components are involving the bird park and deer park. Moreover, the outdoor fitness is clustered as the fourth factor with a single component alone, represents the activities that employed to it are in its own characteristics, probably that involved physical strength and flexibility such as parkour. The second significant finding about this paper (Table 2) was analysed using the Semantic Differential Methodology and also using the principle component analysis and resulted as shown below. Semantic Differential Methodology (SDM) consists of listing the semantic attributes that defined by pairs of antonymous adjectives, which lie at either end of a qualitative scale. 


\begin{tabular}{|c|c|}
\hline \multicolumn{2}{|c|}{ Semantic Differential } \\
\hline Excited & Bored \\
\hline Brave & Shy \\
\hline Hарру & Sad \\
\hline Confident & Scared \\
\hline Outgoing & Annoyed \\
\hline Free & Trapped \\
\hline Peaceful & Agitated \\
\hline Active & Passive \\
\hline Noisy & Quiet \\
\hline Safe & Dangerous \\
\hline
\end{tabular}

Table 1: Result of Semantic Differential

\begin{tabular}{|l|c|c|c|c|}
\hline \multirow{2}{*}{} & \multicolumn{4}{|c|}{ Component } \\
\cline { 2 - 5 } & $\mathbf{1}$ & $\mathbf{2}$ & $\mathbf{3}$ & $\mathbf{4}$ \\
\hline Playground & $\mathbf{. 6 7 2}$ & .084 & .020 & .256 \\
\hline Picnic Area & $\mathbf{. 8 3 6}$ & -.204 & .024 & .076 \\
\hline Parking Area & $\mathbf{. 7 4 0}$ & -.050 & .072 & .139 \\
\hline $\begin{array}{l}\text { Multipurpose } \\
\text { Courts }\end{array}$ & $\mathbf{. 6 7 0}$ & .399 & .238 & -.178 \\
\hline Landscape Area & $\mathbf{. 6 7 0}$ & -.025 & .571 & .069 \\
\hline Water Theme Park & .117 & $\mathbf{. 6 6 3}$ & .363 & .135 \\
\hline Open Space/ Yard & .515 & $\mathbf{. 6 4 6}$ & - & -.217 \\
\hline Cycling Tracks & -.370 & $\mathbf{. 6 7 4}$ & .498 & -.029 \\
\hline Jogging Tracks & -.148 & $\mathbf{. 8 5 8}$ & - & .032 \\
\hline $\begin{array}{l}\text { Toilets/Prayer } \\
\text { Room }\end{array}$ & .071 & $\mathbf{. 6 3 5}$ & - & .535 \\
\hline Bird Park & -.056 & .163 & $\mathbf{. 8 8 8}$ & .110 \\
\hline Deer Park & .412 & -.088 & $\mathbf{. 7 9 0}$ & .055 \\
\hline Outdoor Fitness & .221 & .027 & .203 & $\mathbf{. 8 2 0}$ \\
\hline
\end{tabular}

Table 2: Activity

As a result, based on the above, the skewed significantly towards the left side adjectives. This giving a mean that most of the youth are generally have positive feelings (Table 3 ) towards the park. The result of SDM was analysed further using the principle component analysis in order to cluster the attributes at their best quality. The result of the principle component analysis is shown as (Graph 1) below. 


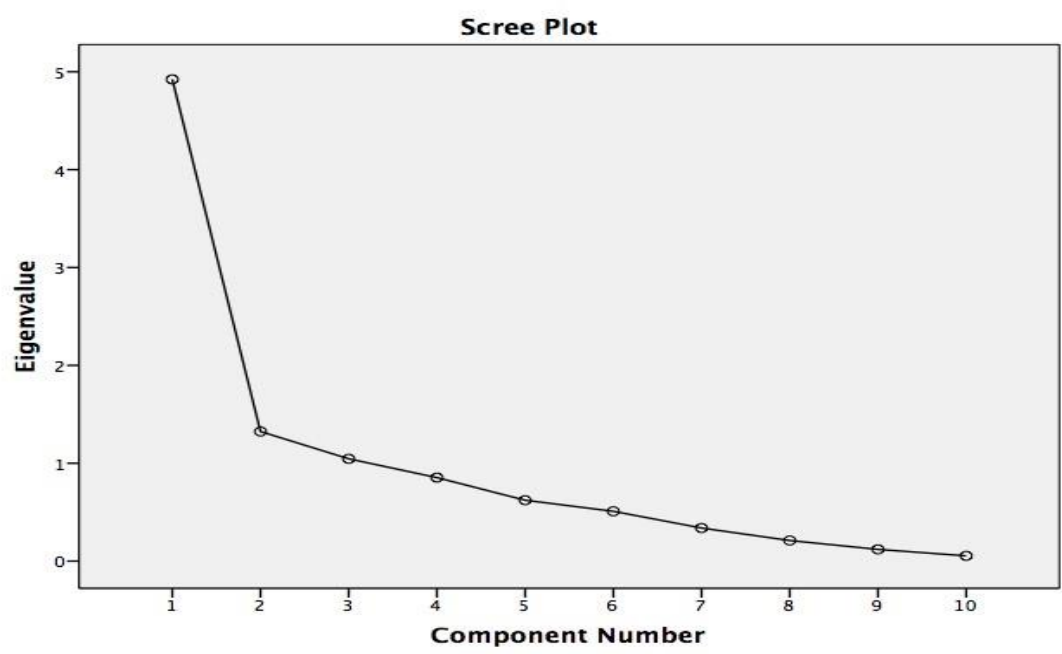

\section{Graph 1: Result of Principle Component Analysis}

Factor analysis investigates the correlations among the subsets of the responses to the bipolar pairs and the groups that have correlated variables, and such that, each group is largely independent of the others. Exploratory factor analysis (Table 3) was employed to identify the groups, which might explain most of the variance in the data. Based on ten pairwise of adjectives given, there are three factors has extracted. The value above 0.5 is significantly selected and clustered. Referring to the result, the third factor consists of single attribute Safe/Dangerous. This adjective probably resembles their concern about themselves regarding the physical environment of the park and also visitors as the threat to themselves. As the attribute is independently alone at its own cluster with higher value at .953 , and skewed left to adjective 'SAFE', youth as the focusing visitors are argued the physical environment at this public park has satisfy their concern about safety. Their exposure towards the current trend and global lifestyle especially in fitness and leisure activities have expanded their views about social-cultural activities in common public park.

\begin{tabular}{|l|l|l|l|}
\hline \multirow{2}{*}{} & \multicolumn{3}{l|}{ Component } \\
\cline { 2 - 4 } & $\mathbf{1}$ & $\mathbf{2}$ & $\mathbf{3}$ \\
\hline Excited/Bored & $\mathbf{. 8 9 1}$ & .088 & - \\
& & & .086 \\
\hline Brave/Shy & $\mathbf{. 7 9 0}$ & .056 & .203 \\
\hline Happy/Sad & $\mathbf{. 8 2 8}$ & .294 & .002 \\
\hline Confident/Scared & $\mathbf{. 7 5 6}$ & .568 & - \\
& & & .063 \\
\hline Outgoing/Annoyed & $\mathbf{. 6 0 0}$ & .402 & .135 \\
\hline Free/Trapped & .358 & $\mathbf{. 6 5 3}$ & .130 \\
\hline Peaceful/Agitated & .433 & $\mathbf{. 7 4 9}$ & .203 \\
\hline Active/Passive & .201 & $\mathbf{. 7 7 8}$ & - \\
& & & .139 \\
\hline Noisy/Quiet & -.020 & $\mathbf{. 7 7 6}$ & .109 \\
\hline Safe/Dangerous & .070 & .092 & $\mathbf{. 9 5 3}$ \\
\hline
\end{tabular}

Table 3: Exploratory Factor Analysis 
In fact, there is cultural exploding and acceptance by the community, some of the functions of the provided facilities unmatched with the activities. It revealed that, the cultural exposures in this park has utilized the physical environment into creative and touristic potential in urban life. As stated by Gehl and Matan (2009), and Low and Smith (2006), the urban places and the utilization may change from day to day and this changing role necessitates the continuous revaluate of the role of public spaces. The public space such as this park has a potential in representing the place of identity sense and that has communication role in bearing the messages. Moreover, the spark of the cultural exploding from this park have exploded to the nearby spaces it where there are socio-cultural activities such as music busking, car booth sale, mini shows also run outside the main entrance of this park.

\section{Conclusion}

Taman Perbandaran Tengku Anis had a spiral socio-cultural changing where the adaptation and rejection of the human activities are accordance to the current lifestyle. This Public Park can be considered as a successful urban public open space in terms of the physical environment designation that offered plenty of human activities onto it. The creativity and potential evolved due to the sociocultural influences and expose through the public assimilation and social media has resulted the park become the identity of urban living in Kota Bharu. The Islamic City labelled to this city unaffected the community socio-cultural exploration and public integration whereas the creativity and touristic potential has increasingly expanded. Youth as the highest potential future visitors to this public park, has promoted successfully the utilization of the facilities provided with positive perceptions about this park. Their expectation and feelings about this park must be taken into consideration by the municipal council and also responsible organization such as the park maintenance office and all visitors of course.

\section{References}

Creighton, J.L., (2005). The Public Participation Handbook. Jossey-Bass, San Francisco, USA. Dobbins, M., (2009). Urban Design and People. John Wiley and Sons.

Gehl, J., \& Matan, A., (2009). Two Perspectives on Public Spaces. In: Building Research \& Information, Vol. 37. No. Routledge, New York. Pp. 106-109.

Isabelle D. Wolf, Heidi K. Stricker \& Gerald Hagenloh (2015) Outcome- focused national park experience management: transforming participants, promoting social well-being, and fostering place attachment, Journal of Sustainable Tourism, 23:3, 358-381, DOI: $10.1080 / 09669582.2014 .959968$

Ismail, W. A. W., \& Said, I. (2015). Integrating the community in urban design and planning of public spaces: a review in Malaysian cities. Procedia-Social and Behavioral Sciences, 168, 357-364.

Jamil, Abu Bakar., (2002). A Design Guide for Public Parks in Malaysia. Penerbit UTM, Skudai Johor Bahru.

Lauren E. Mullenbach, Nicholas A. D. Pitas, Joseph Walker \& Andrew J. Mowen (2018): "It brings the community together": Benefits from local park and recreation renovations, Community Development, DOI: 10.1080/15575330.2018.1527777

Low, S., \& Smith, N., (2006). The Politics of Public Space. Routledge, New York, pp. 2-5.

Khadzali, N. R., \& Zan, Z. M. (2018). E-participation: A systematic understanding on public participation in the government in 21st century. Jurnal Intelek, 13(2), 29-46.

Mario Ianniello, Silvia Iacuzzi, Paolo Fedele \& Luca Brusati (2019) Obstacles and solutions on the ladder of citizen participation: a systematic review, Public Management Review, 21:1, 21-46, DOI: 10.1080/14719037.2018.1438499 
Mohamed Anuar, M., \& Saruwono, M. (2018). Obstacles of Public Participation in the Design Process of Public Parks. Journal Of ASIAN Behavioural Studies, 3(6), 147-155. doi:10.21834/jabs. v3i6.247

Muhammad, S. A. (2019). Playing Pokémon GO in a Public Park in Malaysia: A Survey and Analysis. In Augmented Reality Games I (pp. 177-188). Springer, Cham.

Ngesan, M.R., Karim, H.A., \& Zubir, S.S., (2013). Image of Urban Public Park during Nighttime in Relation to Place Identity. Procedia-Social and Behavioral Sciences, 101, pp. 328337.

Sugiyama, T., \& Ward Thompson, C., (2008). Associations between Characteristics of Neighborhood Open Space and Older People's Walking. Urban Forestry \& Urban Greening, 7(1), pp. 41-51.

Veal, A. J., \& Lynch, R., (2001). Australian Leisure. L 